\title{
Poderia a deliberação enriquecer o reconhecimento?*
}

\section{RESUMO}

O presente artigo busca discutir como a noção de deliberação pública pode dar resposta a alguns dos problemas enfrentados pela teoria do reconhecimento. Para tanto, realizamos um estudo de caso sobre a luta das pessoas atingidas pela hanseníase por recursos financeiros, com foco na indenização dos exilados sanitários. Concluímos que uma ampla deliberação social acerca de políticas de reconhecimento geraria ganhos epistêmicos e de legitimidade, além de implementar, na prática, a noção de um telos em espiral.

\section{PALAVRAS-CHAVE}

deliberação

reconhecimento

hanseníase

\section{ABSTRACT}

This paper aims at discussing how the notion of public deliberation may help to overcome some of the problems faced by the theory of recognition. In order to do so, it investigates the struggle of people affected by Hansen's disease, focusing in the recent financial compensation of those who have been compulsorily segregated. The paper concludes that a wide social deliberation regarding policies of recognition would foster epistemic and legitimacy gains, besides implementing the notion of a spiraling telos.

\section{KEY WORDS}

deliberation

recognition

hansen's disease (leprosy)

\section{Ricardo Fabrino Mendonça}

Doutor em Comunicação Social pela UFMG/MG/BR

ricardofabrino@hotmail.com

\section{Rousiley C. M. Maia}

Professora do Programa de Pós-Graduação em Comunicacão Social da UFMG/MG/BR

rousiley@fafich.ufmg.br
Os conceitos de "deliberação pública" e de "lutas por reconhecimento" têm promovido inovadores debates no campo da teoria política. Esses debates ganharam força, sobretudo, nos anos 1990, com a chamada guinada deliberativa na teoria democrática e a crescente utilização da idéia de reconhecimento para abordar lutas sociais de feições diversas. A partir dos anos 2000, notam-se esforços de aproximar as duas perspectivas (Tully, 2000; 2004; Forst, 2007; Mcbride, 2005; Mendonça; Ayirtman, 2007; Mendonça, 2009).

O presente artigo busca contribuir para esse esforço. Procura-se discutir como a deliberação pode dar resposta a lacunas conceituais e práticas da teoria do reconhecimento. Para tanto, realizamos um estudo de caso sobre a luta das pessoas atingidas pela hanseníase por recursos financeiros, com foco na Lei 11.520 de 2007, que indeniza as vítimas do isolamento compulsório. Investigamos falas proferidas em diferentes esferas comunicativas, constatando a instauração de dinâmicas discursivas distintas e a falta de deliberação mais ampla. Nosso argumento é o de que embates discursivos teriam sido importantes para a instauração de uma refletividade social ampliada e contínua, capaz de viabilizar a construção de soluções legítimas, revisáveis e atentas às alternativas disponíveis. A contribuição do artigo reside na demonstração de que lutas por reconhecimento despidas de deliberação podem conduzir a decisões que não são suficientemente abrangentes e legítimas. A deliberação é essencial se as lutas por reconhecimento são entendidas como processuais.

O artigo está estruturado em três partes. Na primeira, discutimos conceitualmente alguns aspectos relevantes da aproximação entre reconhecimento e deliberação. $\mathrm{Na}$ segunda, contextualizamos a luta das pessoas atingidas pela hanseníase. Na terceira, apresentamos os achados do estudo de caso e derivamos algumas conclusões.

\section{Deliberação e reconhecimento}

A literatura sobre as duas noções aqui em foco é copiosa e diversificada. Tanto o conceito de deliberação ${ }^{1}$ como o de reconhecimento ${ }^{2}$ embasam famílias de abordagens, permeadas por contradições e divergências. No presente artigo, por razões de espaço e escopo, não podemos nos engajar em uma detalhada exposição dessas correntes. Precisamos, contudo, definir, ainda que muito brevemente, nossa compreensão dessas noções.

Sem desconsiderar a relevância de perspectivas focadas no engajamento face-a-face em pequenos fóruns, apoiamo-nos, neste artigo, em uma concepção mais ampla, que entende a deliberação como um processo social de choque de razões, proferidas pública e abertamente. Esse processo pode ganhar concretude por meio de uma ampla gama de formatos comunicativos e depende da 
articulação de diversas esferas discursivas. Para que seja efetivamente pública e social, a deliberação deve atravessar diferentes arenas discursivas (Habermas, 2006; Mansbridge, 1999; Hendriks, 2006; Maia, 2008).

Por "lutas acerca do reconhecimento", compreendemos o conjunto de conflitos moralmente motivados que busca re-articular as gramáticas normativas que regem as interações sociais. Intersubjetivas, essas lutas procuram advogar padrões interativos que fomentem a autorealização. Calcada nas idéias de Axel Honneth, essa concepção não iguala as lutas por reconhecimento a conflitos culturais pela valorização de identidades. Em seu âmago estão os permanentes esforços individuais e coletivos para que a auto-realização seja possível. Nas sociedades contemporâneas, Honneth (2003a) considera que há três reinos fundamentais para a auto-realização: o amor (que permite o reconhecimento de carências e necessidades singulares), os direitos (que lhes garantem um reconhecimento universal) e a estima social (atribuída individualmente de acordo com as contribuições à realização de objetivos sociais).

\section{A hanseníase é uma das doenças mais temidas ao longo da história. Conhecida como lepra e morféia, a enfermidade sempre foi estigmatizada, sendo que suas vítimas viram-se sistematicamente desrespeitadas.}

Partindo dessas proposições gerais, é possível pensar aproximações entre os conceitos aqui em análise. Ainda que haja obstáculos a essas aproximações (McBride, 2005), e que existam deliberacionistas críticos à noção de reconhecimento (Bohman, 2007), acreditamos que essas perspectivas podem se enriquecer. Neste trabalho, não nos propomos a discutir como as lutas por reconhecimento podem afetar processos deliberativos, ainda que tal pergunta seja de relevância fulcral. Ater-nos-emos a abordar a questão inversa, indicando duas contribuições que a concepção deliberacionista pode trazer às lutas por reconhecimento e ao estudo delas.

\section{Mecanismo para lidar com controvérsias e tensões de diversas naturezas}

O modelo do reconhecimento formulado por Honneth permite avaliar a justiça de reivindicações e soluções com base na promoção da auto-realização e na reciprocidade das gramáticas interativas advogadas. Ele deixa em aberto, todavia, situações em que há divergências a respeito dos modos mais adequados para se promover a auto-realização. Muitas vezes, há diversas propostas dos melhores meios para fomentar a possibilidade de auto-realização. Essas propostas podem conceber as injustiças de modos distintos e prescrever remédios diferentes. Em algumas circunstâncias, as diferentes alternativas podem até colocar os reinos do reconhecimento em atrito. Embora Honneth (2003a; 2003b) explore como amor, direitos e estima social são relevantes para a autorealização, ganhos em uma dimensão podem negligenciar ou prejudicar outras. ${ }^{3}$

A perspectiva deliberacionista tem uma importante contribuição aqui. Isso porque a base dessa tradição está ligada à busca de soluções legítimas em contextos marcados por desavenças e múltiplas possibilidades. A preocupação central de autores como Habermas (1997), Bohman (1996), Cohen (1989) e Gutmann \& Thompson (2004) é exatamente a possibilidade de construção da legitimidade mesmo em face de desacordos profundos. A idéia é a de que uma decisão só será legítima se todos aqueles que forem afetados por ela tiverem a oportunidade de se manifestar. Mesmo que a alternativa advogada por alguns sujeitos seja descartada ao longo do processo, há mais chances de eles continuarem cooperando se forem, de fato, ouvidos.

No interior da teoria do reconhecimento, alguns autores chamam a atenção para esse aspecto. Embora adote uma concepção distinta de reconhecimento e o restrinja à dimensão cultural de lutas sociais, Nancy Fraser (2003) argumenta que as soluções para problemas de reconhecimento só podem ser construídas de modo localizado e deliberativo. Mais recentemente, Forst (2007) vem defendendo que é somente através da troca de razões que relações de reconhecimento existentes podem ser criticadas e outras podem ser justificadas.

Importante ressaltar que, para além do caráter legitimador, a troca pública de razões também pode fomentar o refinamento dos argumentos e das soluções propostas. A deliberação entre os concernidos é fundamental para que as alternativas sejam ponderadas coletivamente. Soluções diferentes revelam a existência de, muitas vezes, boas justificativas para cursos de ações distintos. Por meio da deliberação, podem-se pesar os prós e os contras de determinados discursos, suas possíveis implicações e efeitos colaterais. Deliberativamente, os sujeitos podem filtrar argumentos particularistas e articular posições mais abrangentes (Habermas, 2006).

\section{Procedimento de revisibilidade para lidar com a ausência de um telos fixo}

Um problema da teoria do reconhecimento é a ambigüidade da noção de telos que a atravessa. A base hegeliana de autores como Taylor e Honneth leva alguns críticos a afirmar que o reconhecimento visaria a um fim determinado, representado pela valorização de uma concepção específica e sectarista de bem viver. Por outro lado, abrir mão de um telos seria abrir mão de parâmetros normati- 
vos que permitam julgar relações de reconhecimento.

A postura mais interessante é a que pensa o telos como uma espiral que se transforma continuamente (Thompson, 2006; Tully, 2000). Lutas por reconhecimento não podem ser entendidas como conflitos que têm um fim previamente definido a ser alcançado. O telos se transforma continuamente, porque os próprios selves e os elementos importantes à auto-realização estão em permanente transformação. As lutas devem permanecer, assim, sempre abertas e revisáveis (Tully, 2000). Elas devem ser entendidas como parte do processo democrático de instauração de uma refletividade social ampla.

Nesse sentido, processos deliberativos têm uma contribuição muito importante. Isso porque a idéia de revisibilidade está no cerne da noção de deliberação. A troca pública de razões é fundamental para que práticas e justificativas em vigor sejam permanentemente questionadas. No intercâmbio de discursos, sujeitos podem ver suas posições e identidades transformadas (Tully, 2000). $\mathrm{O}$ que argumentamos, em suma, é que a perspectiva deliberacionista ajuda a conceber a operacionalização da abstrata noção de um telos em espiral.

Feita essa breve discussão de possíveis contribuições que a perspectiva deliberacionista tem a oferecer à teoria do reconhecimento, passamos agora a um estudo de caso.

\section{A luta por reconhecimento das pessoas atingidas pela hanseníase}

A hanseníase é uma das doenças mais temidas ao longo da história. Conhecida como lepra e morféia, a enfermidade sempre foi estigmatizada, sendo que suas vítimas viram-se sistematicamente desrespeitadas. Um momento bastante significativo nessa história é o início do século XX, quando diversos países criam, sob a justificativa de defesa da saúde pública, as condições para a segregação massiva de enfermos. No Brasil, até os anos 1960, as pessoas que contraíam a doença eram perseguidas pela polícia sanitária e segregadas em colônias.

O estigma e os sofrimentos impostos às pessoas atingidas pela hanseníase geraram, contudo, uma série de protestos. Desde a descoberta da cura da doença, em 1943, fortaleceram-se as demandas pela abertura das colônias e pela garantia da dignidade. No Brasil, destaca-se a atuação do Morhan (Movimento de Reintegração das Pessoas Atingidas pela Hanseníase), criado, em 1981. Com abrangência nacional, o movimento atua em várias frentes, destacando-se as ações de combate à doença, a batalha contra o estigma, a discussão do futuro das ex-colônias e as lutas por recursos financeiros.

No presente artigo, restringimos nosso foco à última temática. Interessam-nos, especificamente, as discussões em torno da Lei 11.520 de 18 de setembro de 2007, que indeniza as pessoas que foram compulsoriamente segregadas em hospitais-colônia até o ano de 1986, com uma pensão vitalícia de $\mathrm{R} \$ 750,00$. A indenização foi proposta por um projeto de lei (n. ${ }^{\circ} 206$ de 2006) do Senador Tião Viana (PT-AC), que contou com a colabo- ração de ativistas do Morhan. A justificativa do projeto afirma que o Estado deve ressarcir essas pessoas pelos danos irreparáveis causados por uma política governamental.

\section{Essas falas informais apresentam a multidimensionalidade do cotidiano, em um pulular controverso de propostas.}

O projeto despertou uma intensa movimentação no interior dos 33 antigos hospitais-colônia. A coordenação nacional do Morhan discutiu alguns aspectos centrais da proposta, com destaque para a questão das pessoas elegíveis ao benefício e da extensão do mesmo aos filhos de pacientes. Além disso, teve início uma campanha para pressionar a rápida aprovação do projeto, a qual envolveu abaixo-assinados, o trabalho de lobby junto a parlamentares e a realização de manifestações. Em abril de 2007, o Presidente Lula recebeu-os e, um mês depois, editou a Medida Provisória, n. ${ }^{\circ}$ 373, posteriormente aprovada nas duas casas do legislativo. Até o momento, 1093 requerimentos foram deferidos em um total de 25 lotes. Visando a tornar esse processo mais ágil, comitivas do Morhan têm se reunido com autoridades governamentais.

Fica claro, assim, que a lei indenizatória não resolveu de vez o problema de acesso a recursos financeiros das pessoas atingidas pela hanseníase. E isso não apenas porque a implementação de tal lei encontra obstáculos. Todo o processo de discussão e organização dela é atravessado por tensões sobre seus objetivos, seus beneficiários e as próprias justificativas oferecidas para sustentá-la.

Antes de procedermos à análise, contudo, é preciso responder a uma pergunta importante: pode tal luta ser pensada a partir da ótica do reconhecimento? Há, supostamente, dois obstáculos a essa possibilidade. Em primeiro lugar, as pessoas atingidas pela hanseníase não lutam pela valorização de uma identidade grupal, já que não há mérito em ter tido uma doença. Em segundo lugar, há quem distinga as lutas materiais das lutas por reconhecimento.

Somos contrários a essas duas objeções, porque acreditamos que elas partam de concepções distintas de reconhecimento. Na medida em que o reconhecimento é entendido como a luta intersubjetiva moralmente motivada que busca reestruturar gramáticas sociais de modo a possibilitar a auto-realização, não é preciso que se busque uma valorização da coletividade. É preciso lembrar que Honneth fala de uma "simetria da estima", o que não quer dizer que todos devem ser estimados, mas que devem ter a chance de virem a ser estimados (Thompson, 2006). Além disso, essa definição de reconhecimen- 
to não a limita a um conflito cultural. Honneth (2003b) deixa claro que questões distributivas permeiam tanto a construção da dignidade universal, instituída na linguagem dos direitos, como a possibilidade de ser estimado por contribuições específicas à sociedade no trabalho. A questão material também faz parte do modo como a sociedade organiza as suas relações e deve ser alvo de reflexão moral.

\section{As demandas por recursos financeiros em diferentes esferas discursivas}

Para explorar o modo como a questão da indenização foi discursivamente tematizada por pessoas atingidas pela hanseníase, voltamo-nos para três esferas discursivas: 1) conversações informais em antigas colônias; 2 ) edições do Jornal do Morhan publicadas entre 1998 e 2007; e 3) matérias publicadas por Folha de S. Paulo e O Globo no mesmo decênio. ${ }^{4}$ Buscou-se investigar como a questão do acesso a recursos financeiros emerge em distintas esferas comunicativos e constatar se, se pode pensar em um processo deliberativo acerca da questão. Acreditamos que a consolidação de um choque discursivo que atravessa diferentes arenas, poderia trazer as contribuições sugeridas às lutas por reconhecimento.

No presente artigo, não podemos explorar em detalhes todos os argumentos apresentados em cada um desses âmbitos e as múltiplas dimensões que as lutas assumem. Tal empreitada foi desenvolvida na pesquisa de doutorado realizada por um dos autores. ${ }^{5}$

Neste artigo, ater-nos-emos a descrever, em linhas gerais, o teor discursivo encontrado em cada âmbito para que possamos extrair algumas conclusões.

\section{As tensões que atravessam as conversações informais}

Os grupos de conversação que realizamos em cinco hospitais-colônia demonstram que a questão dos recursos financeiros é central à vida dessas pessoas. Essas falas informais apresentam a multidimensionalidade do cotidiano, em um pulular controverso de propostas. Constatou-se, assim, a presença de algumas tensões, merecendo destaque a contraposição entre o "discurso da necessidade" e o da "indenização".

$\mathrm{O}$ "discurso da necessidade" é o mais mobilizado nas falas informais. Ele apregoa a dificuldade das pessoas atingidas pela hanseníase de terem acesso a recursos fundamentais para que tenham uma vida digna. Nesse sentido, trata-se de uma demanda calcada, prioritariamente, no domínio universalizante dos direitos. Muitas falas mostram que as condições de vida dessas pessoas estão muito distantes da idéia de dignidade. Discriminadas em empregos e sem poder trabalhar, muitos se vêem sem ter como garantir a própria subsistência. Um participante de uma conversa em Betim (MG) deixa isso claro:

Rogério: Eu não aguento trabalhar, não. [...] O machucado continua, não agüento trabalhar mais.
Agora se tivesse um beneficio pra nóis era bão. Porque aí eu vou falar a verdade: eu não passo fome não, mas passo quase sem comer, porque o dinheiro não dá pra comprar trem pra comer, não.

\section{Se o "discurso da necessidade" ajuda a mostrar que há questões não contempladas pela indenização, ele pode reforçar 0 estigma do "leproso mendicante incapaz".}

As dificuldades e humilhações na obtenção de aposentadorias limitam ainda mais a vida dessas pessoas. Participantes de um grupo realizado no Acre frisam esse aspecto:

Ronaldo: Foi 35 dia pra fazer a perícia do INSS, pra poder conseguir o beneficio. No fim de conta a doutora [...] chegou pra mim e disse assim: "O INSS não tá pra dar dinheiro pra vagabundo, não". "Só porque o senhor tá doente desse pé?"

Várias pessoas destacam que a doença prejudica as condições de trabalho, até porque muitos ex-pacientes são de áreas rurais e exerciam atividades braçais. A necessidade dos recursos leva alguns a se oporem ao formato da lei 11.520. Argumenta-se que muitas pessoas que nunca foram isoladas também precisam de um benefício, embora a lei as deixe desamparadas.

Carolina: tem um projeto de lei do senador Tião Viana, agora [...] Pras pessoas que saíram das Colônias e tal. Mas eu acho assim, que não é só os que saíram das Colônias. Eu acho...

Nair: Eu também acho...

Paulo: Vamos dizer, uma pessoa que nem eu. Sofri talvez até mais do que o que tá internado. Eu passei meu tempo que era pra tá internado... passei no seringal, dentro da mata, sofrendo. Vamos dizer que a lei do Tião Viana eu não ganho...

Pesquisador: Mas por que todo mundo que teve Hanseníase deveria ter uma indenização do Estado?

Carolina: Porque a pessoa, quando contrai Hanseníase, ele fica impossibilitado de trabalhar.

Nair: Não é uma indenização, é uma pensão vitalícia.

Carolina: Uma pensão! Isso! Vitalícia! [...] A pessoa que teve Hanseníase, ele [...] não pode pegar sol, aí 
ele não tem condições de apoiar um terçado na mão. [...]

Nair: Esse dinheiro serviria exatamente para que o hanseniano tivesse uma vida mais digna.

Os participantes da seqüência empregam o "discurso da necessidade" para se opor ao modo como a indenização foi elaborada. Eles afirmam que a lei não contempla pessoas que sofreram tanto quanto aquelas que foram internadas, nem as que não têm como arcar com a própria subsistência. Os recursos financeiros servem para a universalização da dignidade.

Também crítica é a fala de um morador de Redenção (CE), que afirma que não acha a indenização justa, e que o governo poderia dar esse dinheiro a quem efetivamente precisasse:

Rafael: Olha... eu, pelo menos, eu vivi uma vida boa. [...] Eu num quero esse negócio. Eu tô achando meio errado.

Nas falas informais, também há vozes a defender o discurso da indenização. Essas falas apelam para um complexo jogo entre as dimensões do amor, dos direitos e da estima. Afirma-se que as pessoas segregadas em colônias deveriam ser indenizadas porque suas vidas foram sacrificadas na tentativa de proteger a saúde coletiva. Geralmente, usam-se narrativas de separações familiares e de violências físicas, para defender que o valor da vida dessas pessoas deve ser reconhecido na medida em que elas foram imoladas em prol da sociedade. A ideia é a de que a sociedade tem uma dívida para com os exilados sanitários.

César: você acha que se minha mãe [...] foi internada à força, dentro da colônia, separando ela de mim e dos meus outros irmão. Você acha que o governo não tem uma dívida pra com uma pessoa que foi botada à força na colônia?

Joana: É preciso que as pessoas entendam. [...] Segundo tivemos uma reunião com o Senador lá na Souza Araújo, esse projeto é por conta daquelas pessoas que foram exiladas, afastada da sua família...

Cláudia: É uma indenização.

Joana: É uma indenização pelo o que o governo não deu.

A justificativa indenizatória se faz patente: o dinheiro previsto no projeto de lei serve para reparar um erro do passado. Interessante como Joana deixa ver a existência do enfoque concorrente quando afirma que "é preciso que as pessoas entendam". Com isso, ela mostra a existência de divergências acerca da justificativa da lei. A fala dela aparece como um lance discursivo de um processo mais amplo que ultrapassa essa situação específica.

Cabe observar, ainda, como o "discurso indenizató- rio" pode resolver um problema aberto pelo "discurso da necessidade". Se o "discurso da necessidade" ajuda a mostrar que há questões não contempladas pela indenização, ele pode reforçar o estigma do "leproso mendicante incapaz". A indenização mostra o valor dessas pessoas. Nota-se, assim, que a demanda de um direito pode criar obstáculos à estima, ao passo que uma luta por estima pode deixar escapar aspectos essenciais à vivência da cidadania. Essa tensão poderia ser trabalhada deliberativamente para que as soluções propostas se façam atentas às múltiplas perspectivas em questão.

\section{A luta do Morhan e a apresentação de discursos paralelos no Jornal do Morhan}

A questão do acesso a recursos financeiros tem relativa importância no Jornal do Morhan. Não se trata de um tema abordado com tanta freqüência como esperávamos, sendo que são muito mais recorrentes os enquadramentos da saúde e da mobilização. Ainda assim, encontramos vários textos que fazem menções à questão financeira. Nesses textos, é possível vislumbrar tanto o "discurso da necessidade" como o da "indenização". Diferentemente do observado nas falas informais, contudo, esses discursos existem paralelamente sem se atritar. O Jornal parece muito mais preocupado em demonstrar os esforços e conquistas da luta coletiva do que em promover um embate discursivo.

No corpus analisado, o "discurso da necessidade" aparece, sobretudo, em edições publicadas entre 1998 e 2005. Nessas matérias, salientam-se, em primeiro lugar, diversos obstáculos que impedem a obtenção de recursos essenciais à dignidade. Relatam-se desvios de aposentadorias que deixam ex-pacientes em condição de "extrema pobreza" (JM, n. 26, 1998, p. 7). As colônias abrigariam pessoas que não têm emprego e nem como garantir a própria sobrevivência (JM, n. 40, 2004, p. 8). Tratar-se-ia de "milhões de pessoas" que, "mesmo depois de curadas, não têm oportunidade de estudo e de trabalho" (JM, n. 41, 2005, p. 4). A "hanseníase não é uma doença da pobreza, é uma doença que faz pobreza, porque um incapacitado se empobrece" (JM, n. 36, 2000, p. 4).

Contra essa situação, o Morhan busca criar e apoiar projetos que viabilizem a re-inserção no mercado de trabalho, como cursos profissionalizantes ${ }^{6}$, cooperativas (JM, n. 27, 1999, p. 5) e até um projeto de cirurgias faciais que visa a facilitar a recolocação profissional desses sujeitos (JM, n. 36, 2000, p. 7). Destaca-se a importância dos direitos trabalhistas (JM, n. 30, 1999, p. 10) e reivindica-se o reajuste de benefícios a impossibilitados de trabalhar (JM, n. 33, 2000, p. 4). Todas essas ações contribuiriam para promover a universalização da dignidade.

Curiosamente, o "discurso da necessidade" se vê paulatinamente substituído pelo "discurso da indenização", a partir de meados dos anos 2000. A proposição da lei indenizatória acaba por ofuscar o enfoque da necessida- 
de, sendo que o Jornal do Morhan enfatiza que as pessoas sejam indenizadas pelos sofrimentos a que foram submetidas. Tal ressarcimento se justifica porque "o direito humano daquelas pessoas foi negligenciado" (JM, n. 44, 2006/2007, p. 2). A indenização é "o mínimo que o governo pode dar a essas pessoas" para cumprir o dever humano de "cuidar daqueles exilados sanitários" (JM, n. $44,2006 / 2007$, p. 2).

No jornal reproduzem-se trechos do projeto de lei e se destaca a atuação do movimento em sua construção (JM, n. 43, 2006, p. 4). A matéria mais longa sobre a questão descreve, detalhadamente, a realização do ato público em Brasília (JM, n. 45, 2007, p. 6-7). O Morhan comemora essa concretização de um "sonho" antigo que representaria "o reconhecimento dos direitos das pessoas que foram isoladas compulsoriamente" (JM, n. 45, 2007, p. 2). Tratar-se-ia de um passo "brilhante" no caminho da cidadania, que beneficia não apenas os ex-pacientes, mas "se espelha para toda a sociedade" (JM, n. 43, 2006, p. 2).

O Morhan tenta mostrar, assim, que é fundamental na promoção de gramáticas morais importantes para a consolidação da cidadania de um modo geral. A dimensão da estima se faz clara quando o movimento alega contribuir para a realização de um mundo melhor. Por isso, os ativistas são saudados: "Valeu moradores e moradoras! Vocês foram os grandes protagonistas dessa vitória. Valeu Morhan!" (JM, n. 45, 2007, p. 2).

A presença tanto do "discurso da necessidade" como do "discurso da indenização" poderia sugerir um tratamento das tensões também nessa esfera discursiva. Notase, todavia, que esses discursos não se chocam. Eles existem paralelamente, sem que se notem atritos. Nenhum dos discursos é convocado para mostrar as fraquezas do outro. Esse esvaziamento da tensão em torno da lei é fruto do apagamento do debate em torno dela. $\mathrm{O}$ Jornal do Morhan não dá visibilidade às discussões que permearam o movimento ao longo da confecção e tramitação da lei. Há alusões à existência de discussões, mas essas não são apresentadas. $\mathrm{O}$ foco dado pelo veículo salienta a atuação do coletivo, o esforço e as conquistas de seus ativistas.

Essa dinâmica discursiva pode ser muito eficiente na consolidação da mobilização social. Ela evidencia a dimensão estratégica do jornal de buscar coerência e uniformidade. $\mathrm{O}$ discurso da indenização é apresentado como desprovido de controvérsias. Ele pode ser comparado a um caso já existente (dos exilados políticos) e responsabiliza alguns atores sociais (Estado negligente e sociedade preconceituosa). Se o "discurso da necessidade" apresenta alguns desafios à perspectiva indenizatória, a defesa de um benefício mais geral àqueles que não conseguem se manter poderia ser interpretada como uma espécie de privilégio. Além disso, se o movimento viesse a público discordar da lei, poderia não conseguir benefício algum. Apesar de compreensível, contudo, o apagamento das controvérsias pode comprometer o aper- feiçoamento da solução proposta e contribuir para a redução de sua legitimidade.

\section{A concessão governamental nos jornais da grande mídia}

Nas matérias de Folha de S. Paulo e O Globo, a visibilidade das lutas por reconhecimento das pessoas atingidas pela hanseníase é bastante escassa. O enquadramento da saúde é muito mais recorrente, com destaque para o "esforço de eliminação" e o anúncio de "descobertas científicas". Mas há matérias que deixam aparecer a existência de problemas e questões políticas acerca da hanseníase, sendo que algumas tratam da questão financeira.

Dentre essas, destacamos que os textos que abordam o "discurso da necessidade" são muito raros e aparecem em rápidas menções a um jogador de futebol, que empobreceu depois que contraiu a doença, ${ }^{7}$ e à criação de um programa social no Rio de Janeiro para garantir a alimentação e o transporte de pacientes em tratamento. ${ }^{8}$ Dedica-se um pouco mais de atenção ao "discurso da indenização", que é centralmente abordado por oito matérias. Todas elas foram publicadas por ocasião da assinatura da MP 373 e da aprovação da Lei 11.520.

O Globo acompanha a tramitação da lei desde o anúncio da edição da Medida Provisória. ${ }^{9}$ Afirma-se que o presidente teria se sensibilizado com a história dessas pessoas, sendo que o caráter humanitário do gesto do presidente é ressaltado. ${ }^{10}$ Outra matéria conta que "o presidente Lula se emocionou ontem na solenidade em que autorizou o pagamento de pensão". ${ }^{11}$ A Folha só noticia essa questão quando a lei está prestes a ser aprovada no legislativo. ${ }^{12}$

Em nenhum dos dois veículos, contudo, nota-se a existência de debates em torno da lei. Ao passar pelos crivos da noticiabilidade, a lei viu-se simplesmente noticiada, e a discussão de pontos controversos foi esvaziada. Não se debatem: a justiça da indenização; a quem ela deveria ser destinada; e se ela deveria ou não ser legada a herdeiros. Não se mostra a existência de discussões que precedem a MP. É como se o benefício nascesse pronto e fosse concedido sem controvérsia. De repente, o governo resolveu expressar "o reconhecimento dos direitos das pessoas que foram confinadas". ${ }^{13}$ O presidente inclui a lei entre seus atos para "cuidar dos pobres". ${ }^{14}$ As tensões que atravessam a medida não se manifestam. Também não se menciona que o movimento assessorou parlamentares na confecção do projeto e lutou por sua aprovação. A lei nasce pronta e acabada na caneta do Presidente.

\section{Considerações finais}

Embora sucinta, a síntese de análise apresentada aqui é reveladora. Ela permite ver, antes de tudo, que não se pode falar de um processo deliberativo ampliado acerca da Lei 11.520. A incongruência entre as três esferas discursivas analisadas sugere que, mesmo que a constru- 
ção da lei tenha contado com a participação do movimento social, faltou-lhe um processo discursivo ampliado, envolvendo a sociedade e o conjunto controverso de discursos que atravessa a questão.

As conversações informais demonstram haver potencial deliberativo nessa luta, já que há divergências acerca do formato da pensão governamental e de sua justiça. No entanto, o próprio movimento não deu visibilidade às tensões em torno da lei. Optou-se pela apresentação de um discurso unificado e coerente, que pode fomentar a criação de uma "semântica coletiva" (Honneth, 2003a), mas esvazia a dimensão argumentativa dos discursos. Na medida em que os discursos reiterados não são cotejados a outras possibilidades, e contra-argumentos não são rebatidos, eles se tornam menos legítimos e complexos.

Não queremos, aqui, em hipótese alguma, desmerecer a importância da referida lei. Notamos, contudo, que alguns moradores de colônias permanecem críticos a ela, exatamente porque não viram suas questões respondidas. Entendemos que um processo deliberativo ampliado poderia fomentar a articulação de discursos e o subsequiente refinamento da solução. No entanto, o Morhan parece ter privilegiado a interlocução direta com autoridades governamentais, o que contribuiu para o já existente silêncio sobre a hanseníase na esfera pública. Nas falas informais, constatamos algumas críticas a essa forma de atuação do Morhan. A situação dos egressos de preventórios, por exemplo, não é abordada pela lei. A demanda de que a pensão seja legada aos filhos também não é tratada.

No que concerne às matérias jornalísticas analisadas, constatamos que elas não apenas reproduzem esse apagamento das tensões como acabam por excluir o próprio potencial reivindicatório da luta. A lei se torna uma concessão governamental e não uma conquista de lutas. Não havia uma rede controversa de discursos publicamente disponíveis, e os media não a promoveram. Eles se limitaram a noticiar as medidas governamentais e a celebrar a justiça do ato. Os textos jornalísticos não contribuíram para a existência de um choque de discursos e nem para a promoção da revisibilidade da solução sugerida.

Iniciamos esse artigo com o argumento de que processos deliberativos poderiam ajudar as lutas por reconhecimento a criar soluções mais legítimas, justificáveis e revisáveis. Os achados de nossa análise indicam que, na ausência de deliberação, a legitimação e o refinamento ficaram comprometidos. Seria preciso conduzir estudos sobre outros casos empíricos para verificar se, de fato, em contextos em que se identificam processos deliberativos, podem-se notar ganhos epistêmicos e de legitimidade.

No caso específico das pessoas atingidas pela hanseníase, salientamos que o potencial de revisibilidade permanece aberto. Desde a aprovação da lei, o Morhan realizou alguns protestos contra a morosidade da avaliação dos requerimentos e contra a interpretação do INSS de que o benefício não poderia ser acumulado a outros. Entendemos que o possível desdobramento deliberativo dessas questões na esfera pública ainda se apresenta como possibilidade e pode transformar a lei para articular os discursos que a cercam. O essencial é não julgar que a lei 11.520 resolve os problemas de uma vez por todas afamecos

\section{NOTAS}

Este artigo foi elaborado a partir das discussões apresentadas na tese de doutorado de Ricardo F. Mendonça, intitulada: Reconhecimento e Deliberação: as lutas das pessoas atingidas pela hanseníase em diferentes âmbitos interacionais. O paper foi apresentado no GT de Comunicação e Política do XVIII Encontro da Compós (2009). Agradecemos às contribuições dos participantes do referido congresso, bem como à Fapemig e à Capes pelo apoio na execução da investigação.

1 Incluímos, aqui, autores como Habermas, Cohen, Bohman, Chambers, Gutmann, Thompson, Dryzek, Benhabib, Mansbridge e Cooke. No Brasil, salientamos as pesquisas de Leonardo Avritzer e Rousiley Maia. Para interessantes mapeamentos de perspectivas deliberacionistas, ver Dryzek (2000), Gutmann \& Thompson (2004) e Chambers (2003).

2 Cabe mencionar os trabalhos de Taylor, Honneth, Fraser, Galeotti, Markell, Tully, Kymlicka, Zurn e Seglow. No Brasil, destacamos o trabalho de Jessé Souza. Para uma apresentação de diferentes abordagens da teoria do reconhecimento, ver Thompson (2006), Mattos (2006), Souza (2000) e Mendonça (2007).

3 Este ponto encontra-se desenvolvido e explorado em outro trabalho (Mendonça, 2009)

4 Realizaram-se 12 grupos de conversação em colônias do Acre, Ceará e Minas Gerais. Coletaram-se 43 edições do Jornal do Morhan, sendo 18 analisadas. As matérias jornalísticas foram obtidas nos arquivos eletrônicos das duas publicações. A pesquisa pela palavra hanseníase gerou um corpus de 440 textos.

\section{Mendonça, 2009.}

6 JM, n. 35, 2000, p. 7 / JM, n. 36, 2000, p. 2 / JM, n. 25, 1998, p.13 / JM, n. 25, 1998, p. 14 / JM, n. 26, 1998, p. 5 / JM, n. 28, 1999, p. 4 / JM, n. 35, 2000, p. 9.

7 “Ex-jogador com hanseníase diz que Flu jamais o procurou".O Globo de 31/08/2003, p. 51 "Joel promete que o Flu será ofensivo em Minas". O Globo de 02/09/2003, p. 32.

8 "Secretário vai criar o Cheque-Saúde-Cidadão". O Globo de 14/01/2003, p. 13.

9 "Vítimas de hanseníase receberão R\$760 por mês" $O$ 
Globo de 12/05/2007, p. 11.

10 “Dívida antiga, chaga feia”. O Globo de 24/05/2007, p. 2.

11 "Portadores de hanseníase receberão indenização".O Globo, de 25/05/2007, p. 13.

12 "Governo pagará pensão a exilados por hanseníase". FSP de 02/09/2007.

13 "Governo pagará pensão a exilados por hanseníase".FSP de 02/09/2007.

14 “Dinheiro Público no Ralo". O Globo de 25/05/2007, p.3.

\section{REFERÊNCIAS}

BENHABIB, Seyla. The claims of culture: equality and diversity in the global era. Princeton/Oxford: Princeton University Press, 2002.

BOHMAN, James. Public Deliberation: pluralism, complexity and democracy. Cambridge: MIT, 1996.

“Beyond Distributive Justice and Struggles for Recognition: Freedom, Democracy, and Critical Theory". European Journal of Political Theory, v. 6, n. 3, pp. 267-276, 2007.

CHAMBERS, Simone. "Deliberative Democratic Theory". Annual Review of Political Science, v. 6, pp. 307-26, 2003.

COHEN, Joshua. "Deliberation and Democratic Legitimacy" In: Hamlin, A.; Pettit, P. (Eds.) The Good Polity. Oxford: Basil Blackwell, 1989. pp. 17-34.

DRYZEK, John. S. Deliberative Democracy and Beyond: liberals, critics, contestations. New York: Oxford University Press, 2000.

FORST, Robert. "First things first - Redistribution, recognition and justification". European Journal of Political Theory, v. 6, n. 3, pp. 291-304, 2007.

FRASER, Nancy. "Social Justice in the age of identity politics: Redistribution, Recognition, and Participation". In: FRASER, N; HONNETH, A. Redistribution or Recognition - a political-Philosophical exchange. Londres/Nova York: Verso, 2003. pp. 07-109.

GUTMANN, Amy. THOMPSON, Dennis. Why deliberative democracy? Princeton: Princeton University Press, 2004.

HABERMAS, Jürgen. "Political Communication in Media Society". Communication Theory, v. 16, pp. 411426, 2006.
Direito e democracia: entre a facticidade e a validade. Rio de Janeiro: Tempo Brasileiro, 1997.

HENDRIKS, Carolyn M. Integrated Deliberation: Reconciling Civil Society's Dual Role in Deliberative Democracy. Political Studies, v. 54, n.3, pp. 486-508, 2006a.

HONNETH, Axel. Luta por reconhecimento: a gramática moral dos conflitos sociais. São Paulo: Ed. 34, 2003a.

."Redistribution as recognition: a response to Nancy Fraser". In: FRASER, N; HONNETH, A. Redistribution or Recognition. A political-Philosophical exchange. Londres/Nova York: Verso, 2003b. pp. 110-197.

MAIA, Rousiley. (Coord). Mídia e Deliberação. Rio de Janeiro: Editora FGV, 2008.

MANSBRIDGE, Jane. Everyday Talk in Deliberative System. In: MACEDO, Stephen (ed.). Deliberative Politics: essays on democracy and disagreement. NY: Oxford University Press, 1999. pp. 211-239.

MCBRIDE, Cillian. "Deliberative democracy and the politics of recognition". Political Studies, Oxford, v. 53, n. 3, pp. 497-515, 2005.

MENDONÇA, Ricardo. F. Reconhecimento em debate: os modelos de Honneth e Fraser em sua relação com o legado habermasiano. Revista de Sociologia e Política, n. 29, pp. 169-185, 2007.

Reconhecimento e Deliberação: as lutas das pessoas atingidas pela hanseníase em diferentes âmbitos interacionais. Tese (Doutorado em Comunicação Social) FAFICH, Universidade Federal de Minas Gerais, Belo Horizonte, 2009.

AYIRTMAN, Selen. Discourses of recognition in contemporary politics. Texto apresentado em New Horizons in Political Philosophy, Canberra (Australia), 6-7 Dez., 2007.

SOUZA, Jessé. “Uma teoria crítica do reconhecimento". Lua Nova, n.50, pp. 133-158, 2000.

THOMPSON, Simon. The Political Theory of Recognition: A Critical Introduction. Cambridge: Polity, 2006.

TULLY, James. "Struggles over Recognition and Distribution". Constellations, v.7, n. 4, pp.469-482, 2000.

"Recognition and Dialogue: The Emergence of a New Field". Critical Review of International Social and Political Philosophy, vol. 7, n. 3, pp. 84-106, 2004. 